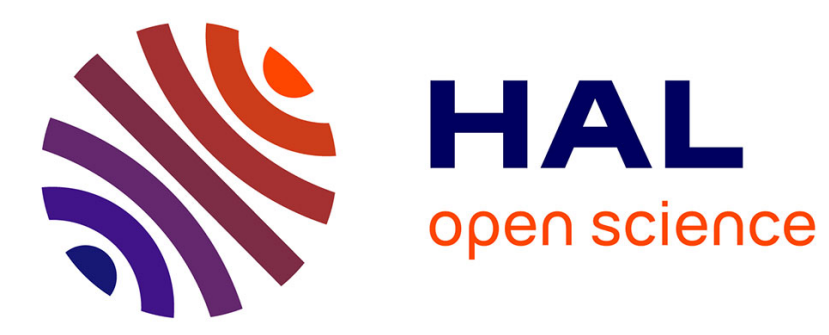

\title{
N.M.R. orbital shifts of 125 Te in solids, dependence on ionicity and local structure
}

\author{
A. Willig, B. Sapoval
}

\section{To cite this version:}

A. Willig, B. Sapoval. N.M.R. orbital shifts of 125 Te in solids, dependence on ionicity and local structure. Journal de Physique Lettres, 1977, 38 (2), pp.57-60. 10.1051/jphyslet:0197700380205700 . jpa-00231324

\section{HAL Id: jpa-00231324 https://hal.science/jpa-00231324}

Submitted on 1 Jan 1977

HAL is a multi-disciplinary open access archive for the deposit and dissemination of scientific research documents, whether they are published or not. The documents may come from teaching and research institutions in France or abroad, or from public or private research centers.
L'archive ouverte pluridisciplinaire HAL, est destinée au dépôt et à la diffusion de documents scientifiques de niveau recherche, publiés ou non, émanant des établissements d'enseignement et de recherche français ou étrangers, des laboratoires publics ou privés. 


\author{
Classification \\ Physics Abstracts \\ $8.134-8.138-8.520-8.662$
}

\title{
N.M.R. ORBITAL SHIFTS OF ${ }^{125}$ Te IN SOLIDS, DEPENDENCE ON IONICITY AND LOCAL STRUCTURE
}

\author{
A. WILLIG and B. SAPOVAL
}

Laboratoire de Physique de la Matière Condensée $(*)$, Ecole Polytechnique, 91120 Palaiseau, France

(Reçu le 27 juillet 1976, révisé le 28 octobre 1976, accepté le 20 décembre 1976)

\begin{abstract}
Résumé. - Le déplacement orbital de la R.M.N., qui mesure la participation des états non-s aux liaisons chimiques, peut être relié directement à l'ionicité dans les composés du tellure. Dans une description moléculaire du solide négligeant les états $d$, ce déplacement varie de façon parabolique avec le nombre d'électrons $\mathrm{p}$ dans les bandes de valence. Ce nombre, qui dépend de façon simple de l'ionicité pour les liaisons du tellure, peut être modifié lors d'un changement de la symétrie locale, en particulier lors de l'amorphisation.
\end{abstract}

\begin{abstract}
The orbital chemical shift of N.M.R., which measures the weight of non-s states in the chemical bond, can be related directly to the ionicity for tellurium compounds. In a molecular picture of the solid neglecting $\mathrm{d}$ states, the shift is a parabolic function of the number of $\mathrm{p}$-electrons in the valence band. This number depends simply on the ionicity for tellurium bonds and can be modified by change in the local symmetry, especially by amorphization.
\end{abstract}

A number of compounds of tellurium with a large variety of chemical structures have been studied by N.M.R. It is known that the paramagnetic chemical shift (C.S.) of N.M.R. is related to the covalency of the chemical bonds. We present here a recollection of ${ }^{125} \mathrm{Te}$ N.M.R. measurements together with new results and we show that a very simple model relates chemical shifts to ionicities, enabling us to measure directly ionicity from chemical shift. In this simplified molecular picture of the solid the chemical shift is a function of the number of $p$ valence electrons around tellurium atoms. This number of p-electrons depends in general on the ionicity and the local symmetry but in the case of tellurium it can be obtained, in a first approximation, from the ionicity only.

The paramagnetic C.S. of the N.M.R. frequency is due to the hyperfine field created on the nuclei by the valence shells in which the orbital momentum has been partially dequenched by the external magnetic field [1]. The induced orbital momentum is also responsible for the Van Vleck paramagnetism, a closely related phenomenom [2]. A simplified expression of the paramagnetic C.S. is given by Jameson and Gutowsky [3] for molecules, in a closure approxi-

$\left(^{*}\right)$ Equipe de Recherche du Centre National de la Recherche Scientifique. mation. Neglecting the contribution of $d$ states, the isotropic part of the paramagnetic shift is given by

$$
\sigma_{\mathrm{p}}=-\frac{\mu_{0}}{4 \pi} \frac{2}{3} \mu_{\mathrm{B}}^{2}\left\langle r^{-3}\right\rangle_{\mathrm{p}} \cdot \frac{P_{\mathrm{u}}}{\Delta}
$$

where $\mu_{\mathbf{B}}$ is the Bohr magneton, $\Delta$ is the mean excitation energy between valence and excited states and $\left\langle r^{-3}\right\rangle_{p}$ is the mean value of $r^{-3}$ between outer $\mathrm{p}$ orbitals of the atom under consideration.

The quantity $P_{\mathrm{u}}$ is defined by these authors as the unbalanced content of the $\mathrm{p}$ shell, and involves projectors on $p_{x}, p_{y}, p_{z}$ states. It is zero for an empty of closed $\mathrm{p}$ shell which is spherical. In a tetrahedral or cubic site, $P_{\mathrm{u}}$ takes the particularly simple form [4] :

$$
P_{\mathrm{u}}=N_{\mathrm{p}}\left(1-N_{\mathrm{p}} / 6\right)
$$

where $N_{\mathrm{p}}$ is the total weight of tellurium $\mathrm{p}$ outer atomic orbitals in the valence states of the compound of interest. We show in this paper that the C.S. is mainly determined by the value of $P_{u}$, the mean excitation energy $\Delta$ changing only slightly from one compound to the other.

We now relate the quantity $N_{\mathrm{p}}$ to the ionicity. The ionicity represents the sharing of the valence electrons in the bonds between anions and cations. It is defined in the following way by Harrison [5]: If $\left|h_{\mathrm{a}}\right\rangle$ and $\left|h_{\mathrm{c}}\right\rangle$ are respectively the hybridized atomic orbitals 
of the anion and cation, the bond orbital $|b\rangle$ is written

$$
|b\rangle=\left(\frac{1+\alpha_{\mathrm{p}}}{2}\right)^{1 / 2}\left|h_{\mathrm{a}}\right\rangle+\left(\frac{1-\alpha_{\mathrm{p}}}{2}\right)^{1 / 2}\left|h_{\mathrm{c}}\right\rangle
$$

where $\alpha_{p}$ is the polarity, or chemical ionicity. (Note that $\alpha_{p}$ is slightly different from the spectroscopic ionicity $f_{\mathrm{i}}$ defined by Phillips [6]). It is shown in ref. [5] that :

$$
\left(1-f_{\mathrm{i}}\right)=\left(1-\alpha_{\mathrm{p}}^{2}\right)^{3 / 2} \text {. }
$$

In binary compounds for which the values of $\alpha_{p}$ or $f_{\mathrm{i}}$ have been published $[7,8]$, we use these values to determine the total weight of tellurium orbitals in the valence states, $N_{\text {anion }}$.

In tellurium compounds we neglect the contribution of tellurium $5 \mathrm{~s}$ states to the excited states because the splitting between $5 s$ and $5 p$ states of tellurium is large and their hybridization is weak. (The relation (3) still holds in an hybridization different from pure $\mathrm{sp}^{3}$ ). Then we write [9] :

$$
N_{\mathrm{p}}=N_{\text {anion }}-2 \text {. }
$$

In zinc blende (N, VIII-N) compounds, such as $\mathrm{ZnTe}, \mathrm{CdTe}, \mathrm{HgTe}$, the eight valence electrons are in bonding orbitals :

$$
N_{\mathrm{p}}=2+4 \alpha_{\mathrm{p}} .
$$

In IV-VI compounds with rocksalt structure such as $\mathrm{PbTe}, \mathrm{SnTe}$, six valence electrons are in the bonding p orbitals with the ionicity $\alpha_{p}$, the four other electrons fill deeper orbitals localized around each atom [10] $\left(\mathrm{s}_{2}, \mathrm{p}_{3}\right.$ hybridization) :

$$
N_{\mathrm{p}}=3\left(1+\alpha_{\mathrm{p}}\right) \text {. }
$$

In pure tellurium, within the same approximation we obtain $N_{\mathrm{p}} \sim 4$. We use relation (2) giving $P_{\mathrm{u}}$ to calculate the isotropic part of the paramagnetic C.S. because the structure of crystalline tellurium is not very different from tetrahedral.

We have no ionicity value for the $\mathrm{TeCl}_{2}$ molecule, but from the chemical properties and the molecule geometry, we evaluate [11] $N_{\mathrm{p}} \sim 3.3 ; P_{\mathrm{u}} \sim 1.6$.

In order to determine a C.S. one needs two frequencies, the N.M.R. frequency of the compound (after correction for a possible Knight shift) and the frequency of a compound with an empty valence shell, here $\mathrm{Te}^{6+}$. Such a compound does not exist $\left(\mathrm{TeCl}_{2}\right.$ often quoted as a reference is the most paramagnetic among tellurium compounds and cannot be used as a reference). In the lack of an experimental reference we use a detailed theory of the C.S. in CdTe given elsewhere [12]. This calculation, together with the experimental frequency of CdTe, gives us a theoretical reference :

$$
\gamma_{\mathrm{Te}^{6+}}=13.379 \mathrm{MHz} / \mathrm{T} .
$$

We show in table I the experimental and theoretical data on compounds where both chemical structure

\begin{tabular}{|c|c|c|c|c|c|}
\hline & Ionicity & & & & \\
\hline Compound & $f_{\mathrm{i}}$ & $N_{\mathrm{p}}$ & (ppm) & (ppm) & Reference \\
\hline - & - & & - & - & - \\
\hline $\mathrm{Te}$ & 0 & 4 & -4810 & -4860 & [13] \\
\hline CdTe & 0.717 & 5.01 & -2800 & -2860 & {$[4]$} \\
\hline $\mathrm{HgTe}$ & 0.65 & 4.84 & -2900 & -2960 & [4] \\
\hline $\mathrm{ZnTe}$ & 0.609 & 4.72 & -2916 & -2976 & $\begin{array}{l}\text { our measu- } \\
\text { rements }\end{array}$ \\
\hline $\mathrm{PbTe}$ & 0.65 & 5.12 & -2310 & -2370 & [14] \\
\hline SnTe & 0.49 & 4.8 & -2840 & -2900 & [15] \\
\hline $\mathrm{TeCl}_{2}$ & & $\sim 3.3$ & -5410 & -5450 & [16] \\
\hline
\end{tabular}
and N.M.R. results are known. The values of $\sigma_{\mathrm{p}}$ are obtained from the total chemical shift $\sigma$ by substracting the small value of the diamagnetic C.S. which is estimated from the number of valence electrons [12].

\section{TABLE I}

(Te dissolved

in aqua regia)

The values of $f_{\mathrm{i}}$ are taken from ref. [7] for zincblende compounds and from ref. [8] for $\mathrm{PbTe}$ and $\mathrm{SnTe}$. $\sigma_{\exp }$ is obtained from experiment by deducing the theoretical reference frequency of $\mathrm{Te}^{6+}$ discussed in the text. The paramagnetic C.S. $\sigma_{\mathrm{p}}$ is obtained by correcting $\sigma_{\exp }$ for the (small) diamagnetic C.S.

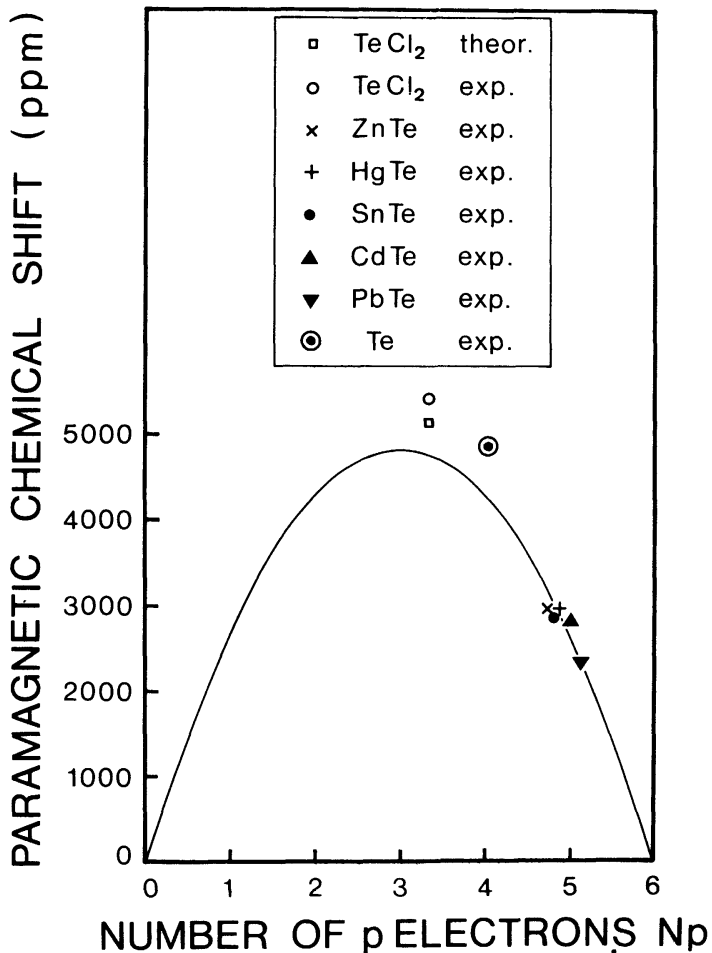

Fig. 1. - Experimental and theoretical paramagnetic chemical shifts of ${ }^{125} \mathrm{Te}$ N.M.R. in tellurium compounds, as a function of the number of $p$ valence electrons around tellurium : The curve represents the theoretical value calculated from our model for compounds with a tetrahedral or cubic symmetry. The square represents the theoretical value of the shift of the lower symmetry molecule $\mathrm{TeCl}_{2}$, using the same model. The experimental points give, for each compounds, the measured paramagnetic chemical shift ; the values of $N_{\mathrm{p}}$ in abscissa are obtained as described in the text. 
Comparison between our model and experiment is shown in figure 1 . The curve represents the theoretical value of $\sigma_{\mathrm{p}}$ given by eq. (1) for cubic compounds with $\left\langle r^{-3}\right\rangle_{\mathrm{p}}=11.9$ a.u. [17] and $\Delta=3.55 \mathrm{eV}$. The square represents the theoretical value of $\sigma_{p}$ for the case of the lower symmetry molecule $\mathrm{TeCl}_{2}$ for which the formula (2) is not correct [11]. For all these compounds we plot in the same figure the experimental points $\left(\sigma_{\mathrm{p}}, N_{\mathrm{p}}\right)$. The agreement between such a simplified model and experiment is remarkably good. This shows that the main factor governing C.S. is the content of $p$ orbitals around the nuclei in the solid. A few comments can be made: The mean excitation energy $\Delta$ which enters the C.S. is analogous to the mean gap between valence and conduction band $E_{g}$ although it is not defined through the same kind of average over the Brillouin zone [6, 18]. The values of $E_{g}$ given by Phillips [6] range from $4.98 \mathrm{eV}$ for BeTe to $5.79 \mathrm{eV}$ for CdTe. This agrees with the quasi constant $\Delta$ that we observe. The tellurium experimental point is above the theoretical curve, illustrating that there is no ionic contribution to the gap of homopolar compounds.

A quantity closely related to the paramagnetic C.S. of the N.M.R. is the Van Vleck paramagnetic susceptibility $\chi_{\mathbf{v v}}$ which measures the macroscopic orbital paramagnetism [19]. Both quantities are simply related by a relation of the form

$$
\chi_{\mathrm{vv}} \sim-\frac{1}{\Omega}\left(\frac{\sigma_{\mathrm{pA}}}{\left\langle r^{-3}\right\rangle_{\mathrm{A}}}+\frac{\sigma_{\mathrm{pB}}}{\left\langle r^{-3}\right\rangle_{\mathrm{B}}}\right)
$$

in the case of an $\mathrm{AB}$ compound of unit cell $\Omega$. Here $\sigma_{\mathrm{pA}}$ and $\sigma_{\mathrm{pB}}$ are respectively the paramagnetic C.S. of atoms $\mathrm{A}$ and $\mathrm{B}$ and $\left\langle r^{-3}\right\rangle_{\mathrm{A}},\left\langle r^{-3}\right\rangle_{\mathrm{B}}$ are the atomic averages over $\mathbf{p}$ orbitals in atoms $\mathbf{A}$ and $\mathbf{B}$.

Chadi et al. [20] have calculated $\chi_{\mathrm{vv}}$ of several binary compounds, in a model slightly different from ours $[9,21]$. A comparison between their results and ours can be made in $\mathrm{HgTe}, \mathrm{CdTe}$, and gives good agreement [21].
From the above study we can now predict the effect of a change of $N_{\mathrm{p}}$ on orbital paramagnetism. An increase of $N_{\mathrm{p}}$ will cause an increase of the paramagnetic C.S. when $N_{\mathrm{p}}<3$; on the contrary if $N_{\mathrm{p}}>3$ it will cause a decrease of the paramagnetic C.S. hence a diamagnetic displacement of the N.M.R. line.

An example of an increase of $\sigma_{\mathrm{p}}$ with $N_{\mathrm{p}}$ is given by the variation of the C.S. of ${ }^{199} \mathrm{Hg}$ in $\mathrm{Hg}_{1-x} \mathrm{Cd}_{x} \mathrm{Te}$ alloys, a case which is extensively studied in ref. [12]. Here the substitution of $\mathrm{Cd}$ atoms as second neighbours of $\mathrm{Hg}$ increases the $\mathrm{p}$ content of the bonds. ( $N_{\mathrm{p}}$ changes from 0.3 to 1.2.) An other example of an increase of $N_{\mathrm{p}}$ is that due to the lowering of the local symmetry by amorphization in $\mathrm{TlAsSe}_{2}$ [22]. Here the ${ }^{205} \mathrm{Tl}$ resonance occurs in higher field in polycrystalline samples that in the amorphous material.

On the contrary the lowering of the local symmetry will cause a decrease of the paramagnetic C.S. if we start from $N_{\mathrm{p}}>3$. This is the case of the material $\mathrm{Te}_{81} \mathrm{Ge}_{15} \mathrm{As}_{4}$ which undergoes a diamagnetic shift of the N.M.R. of ${ }^{125} \mathrm{Te}$ between crystalline and amorphous states [23]. In this compound the C.S. value in the crystalline state indicates that $N_{\mathrm{p}} \sim 4$.

The same mechanism could participate in the change of magnetic susceptibility between crystalline and amorphous states [24, 25, 26]. In polyatomic compounds one sees from eq. (4) that it is possible to observe diamagnetic or paramagnetic enhancement depending on which of $\left|\delta \sigma_{\mathrm{pA}}\right|$ or $\left|\delta \sigma_{\mathrm{pB}}\right|$ is greater when the symmetry is lowered. In the case of germanium [24] we think that the increase of $N_{\mathrm{p}}$ from $N_{\mathrm{p}}=3$ could partially explain the diamagnetic enhancement between the crystalline and amorphous states $[18,27]$ although the maximum value $N_{\mathrm{p}}=4$ accounts for only one fourth of the observed variation. This could be due to the fact that states participating principally to orbital magnetism (not too far in energy) are more strongly perturbed by amorphization than the mean bond orbital, a fact which is out of the simplified picture that we propose.

\section{References}

[1] Ramsey, N. F., Phys. Rev. 78 (1950) 699.

[2] VAN VleCK, J. H., The Theory of Electric and Magnetic Susceptibility (Oxford) 1932, p. 277.

[3] Jameson, C. J. and Gutowsky, H. S., J. Chem. Phys. 40 (1964) 1714.

[4] Willig, A., Thesis, Université de Paris-Sud (1976).

[5] Harrison, W., Phys. Rev. B 10 (1973) 4487.

[6] Phillips, J. C., Phys. Rev. Lett. 20 (1968) 550.

[7] Phillips, J. C., Bonds and Bands in Semiconductors (Academic Press, New York) 1973, p. 42.

[8] Stiles, P. J., Solid State Commun. 11 (1972) 1063.

[9] Most Bond-orbital calculations take $N_{\mathrm{p}}=3 / 4 N_{\text {anion }}$ in tetrahedral compounds; then $N_{\mathrm{p}}=3\left(1+\alpha_{\mathrm{p}}\right)$, and $P_{\mathrm{u}_{\text {anion }}}=P_{\mathrm{u}_{\text {cation }}}=3\left(1-\alpha_{\mathrm{p}}^{2}\right) / 2$ in both $(\mathrm{IV}-\mathrm{VI})$ and (N, VIII-N) compounds.

[10] Lucovsky, G. and White, R. M., Phys. Rev. 8 (1973) 660.
[11] The $\mathrm{TeCl}_{2}$ molecule has a strong covalent character (weak solubility; bond angle of $\left.99^{\circ}\right)$. A S.C.F. calculation in the similar molecule $\mathrm{SCl}_{2}$ (bond angle of $101^{\circ}$ ) yields $N_{\mathrm{p}}=3.7$. As tellurium atomic levels stand higher than sulphur levels, $N_{\mathrm{p}}$ is weaker and we take $N_{\mathrm{p}}=3.3$. The calculation of $P_{\mathrm{u}}$ from ref. [3] and the geometry of the molecule gives $P_{\mathrm{u}}=1.6$.

[12] Willig, A., Sapoval, B., Leibler, K. and Verie, C., J. Phys. C 9 (1976) 1981.

[13] Bensoussan, M., J. Phys. Chem. Solids 22 (1967) 1533.

[14] Sapoval, B., Thesis, Université de Paris (1966).

[15] Senturia, J. D., Smith, A. C., Hewes, C. R., Adler, M. S., Hoffman, J. A. and Sagalyn, P. L., Conference on Physics of Semimetals and Narrow Gap Semiconductors (Ed. : D. L. Carter and R. T. Bate, Pergamon) 1970, p. 333. 
[16] Dharmatti, S. S. and Weaver, H. E., Phys. Rev. 84 (1951) 843.

[17] Fischer, C. F., Some Hartree-Fock Results from the Atom Helium to Radon, QTG, Department of Applied Mathematics, University of Ontario, Canada (1969).

[18] Hudgens, S., Kastner, M. and Fritzche, H., Phys. Rev. Lett. 33 (1974) 1552.

[19] Koma, A. and TanaKa, S., Solid State Commun. 10 (1972) 823.

[20] Chadi, D. J., White, R. M. and Harrison, W. A., Phys. Rev. Lett. 35 (1975) 1372.

[21] We compare

$$
\left[\left(\frac{P_{\mathrm{u}}}{\Delta}\right)_{\text {anion }}+\left(\frac{P_{\mathrm{u}}}{\Delta}\right)_{\text {cation }}\right]
$$

with the equivalent quantity in ref. [20] :

$$
\frac{3 \lambda^{2}\left(1-\alpha_{\mathrm{p}}^{2}\right)}{E_{\mathrm{a}}-E_{\mathrm{b}}}
$$

parameters involving the cation $\mathrm{Hg}, \mathrm{Cd}$ are drawn from ref. [4]. Our values are 0.33 (HgTe), 0.298 (CdTe) ; Chadi's values are 0.283 ( $\mathrm{HgTe}), 0.297$ (CdTe).

[22] Baidakou, L. A., Kudryavtsea, A. N. and Novoselou, S. K., Izvestiya Akademii Nauk SSSR, Neorganischeskie Materialy 9 (1973) 1640.

[23] Brown, D., Moore, D. S. and Seymour, E. F. W., J. NonCryst. Solids 8 (1972) 256.

[24] Hudgens, S. J., Phys. Rev. B 7 (1973) 2481.

[25] Cervinka, L., Hruby, A., Matyas, M., Simecek, T. Skacha, J., Stourac, L., Tauc, J., Vorlicek, V. and Hoschl, P., J. Non-Cryst. Solids 4 (1970) 258.

[26] Matyas, M., Phys. Status Solidi 43 (1971) K63.

[27] White, R. M. and Anderson, P. W., Phil. Mag. 25 (1972) 737. 